\title{
DESCRIÇÃO DE UMA ESPÉCIE NOVA DE CALYOZINA ENDERLEIN (HYMENOPTERA, BETHYLIDAE) DO BRASIL
}

\author{
Celso Oliveira Azevedo ${ }^{1}$
}

\begin{abstract}
DESCRIPTION OF A NEW SPECIES OF CALYOZINA ENDERLEIN (HYMENOPTERA, BethylidaE) From Brazil. Calyozina dilatata sp.n., from northern Brazil is described and illustrated. This species is recognized by having the fifth foretarsomere dilated. With six scanning micrografies.

KEY WORDS. Hymenoptera, Bethylidae, Calyozina, Neotropical region, pectinate antennae
\end{abstract}

Este gênero foi descrito a partir de uma espécie paleártica, C. ramicornis, por ENDERLEIN (1912). EVANS $(1964,1965,1978)$ descreveu quatro espécies para a região neotropical e KROMBEIN (1990) descreveu a única espécie afrotropical conhecida.

As espécies de Calyozina Enderlein, 1912 são caracterizadas por terem antenas pectinadas nos machos. As fêmeas não são conhecidas.

Para Evans (1978) Calyozina é um gênero relacionado com Epyris Westwood, 1832; mas a forma das covas escutelares e o perfil das margens anterior e lateral do disco pronotal são semelhantes aos encontrados em Bakeriella Kieffer, 1910.

KROMBEIN (1992) estudou os gêneros de Epyrinae cujos machos têm antenas pectinadas, quando considerou Calyoza Westwood, 1837, Paracalyoza Cameron, 1909, Calyozella Enderlein, 1920 e Pseudocalyoza Turner, 1915 como sinônimos juniores de EpyrisWestwood, 1832, e Calyozina Enderlein, 1912 como um gênero distinto.

Encontram-se ainda espécies com antenas pectinadas em Procalyoza Kieffer, 1905, gênero relacionado com Anisepyris Kieffer, 1905, principalmente, por ter o disco pronotal carenado ântero-lateralmente. Apenas o macho é conhecido e é possivel que a fêmea tenha antena não pectinada (EvANS 1964), podendo ser erroneamente alocada em Anisepyris. Talvez Procalyoza mereça não mais do que status subgenérico em Anisepyris (EvANS 1964).

Antenas pectinadas não são incomuns em Epyrinae, tenho observado exemplares machos de Rhabdepyris Kieffer, 1904 com este tipo de antena, porém com processos não muito desenvolvidos. Até o presente, não foi descrita nenhuma espécie deste gênero cujo o macho tenha antenas pectinadas.

1) Departamento de Biologia, Universidade Federal do Espírito Santo, Avenida Marechal Campos 1468, 29040-090 Vítória, Espírito Santo, Brasil.

e-mail: cazevedo@npd1.ufes.br. 
O material estudado pertence à Coleção Entomológica do Instituto Nacional de Pesquisa da Amazônia (INPA) e representa uma espécie nova de Calyozina.

As abreviações usadas seguem EVANS (1964) e a nomenclatura referente à textura do tegumento segue HARRIS (1979). As micrografias foram feitas em microscópio eletrônico de varredura a partir de um exemplar coberto com prata. Todas as escalas apresentadas nas ilustrações são em micrômetros.

\section{Calyozina dilatata sp.n.}

Figs 1-6

\section{$2,0 \mathrm{~mm}$. \\ Descrição. Holótipo macho. Corpo delgado, comprimento 3,4mm; LFW}

Cores. Cabeça e mesosomo pretos; gáster preto com a porção terminal dos segmentos marrom-avermelhadas, antena marrom-escura; mandíbula com a porção basal preta, transformando-se em castanha no ápice, dentes mais escuros; palpos castanho-claros; clípeo preto; coxas pretas, trocânteres castanhos, o posterior mais escuro, fêmures e tíbias castanho-escuros, porção basal do fêmur mediano mais clara, tarsos castanho-claros; asas fortemente tingidas de marrom, exceto o quinto apical hialino, nervuras castanho-escuras.

Cabeça (Fig. 1). Mandíbula com dois dentes apicais, o superior menor do que o inferior. Clípeo curto, com uma carena mediana tranversal completa, reta no perfil, margem apical com um lobo mediano arredondado. $\mathrm{LH} 1,17 \mathrm{X} \mathrm{WH}$; fronte ampla, WF 0,74 X WH; WF 1,21 X HE, olho grande, pouco convergente anteriormente; WOT $0,89 \times$ OOL, triângulo ocelar amplo e próximo do vértice, ocelo posterior distante do vértice $0,3 \mathrm{X}$ DAO; ângulo frontal do triângulo ocelar obtuso; vértice ligeiramente convexo com cantos arredondados. Cabeça pouco desenvolvida atrás dos olhos. Olho glabro. Segmentos antenais III-XII (Figs 2, 3) com processos finos, ligeiramente arqueados e pilosos, que nascem na face externa da porção distal dos segmentos e são maiores nos segmentos medianos, onde são 1,67 vezes mais longos do que o próprio segmento (segmento VI) e diminuem progressivamente de tamanho, tanto apicalmente $(0,5$ vezes mais longo do que o segmento X II) como basalmente ( 1,0 vez mais longo do que o segmento III). Segmento III curto, razão entre os quarto primeiros segmentos antenais de 8:7:6:9; sensilas antenais inconspícuas, alongadas, mais densas na porção distal de cada segmento. Fronte fracamente imbricada (Fig. 4), com poucas pontuações extremamente pequenas e distantes umas das outras 10 vezes seus diâmetros.

Mesosomo (Fig. 5). Dorso do tórax com a textura muito ligeiramente mais forte do que a da fronte e com pontuações um pouco mais próximas, no escutelo as pontuações são um pouco maiores e distantes umas das outras 1-3 vezes seus diâmetros. Tórax mais largo na margem posterior do pronoto, porém não mais largo do que a cabeça. Disco pronotal desprovido de carenas, mas com lobo anterior cônico, disco com largura mediana 1,73 vezes seu comprimento. Notáulice retilínea, completa, alargada e convergente posteriormente. Sulco parapsidal retilíneo, fino e não atingindo as margens anterior e posterior do mesoscuto, porém muito próximo desta última. Escutelo com duas covas anteriores grandes e arredondadas, não 


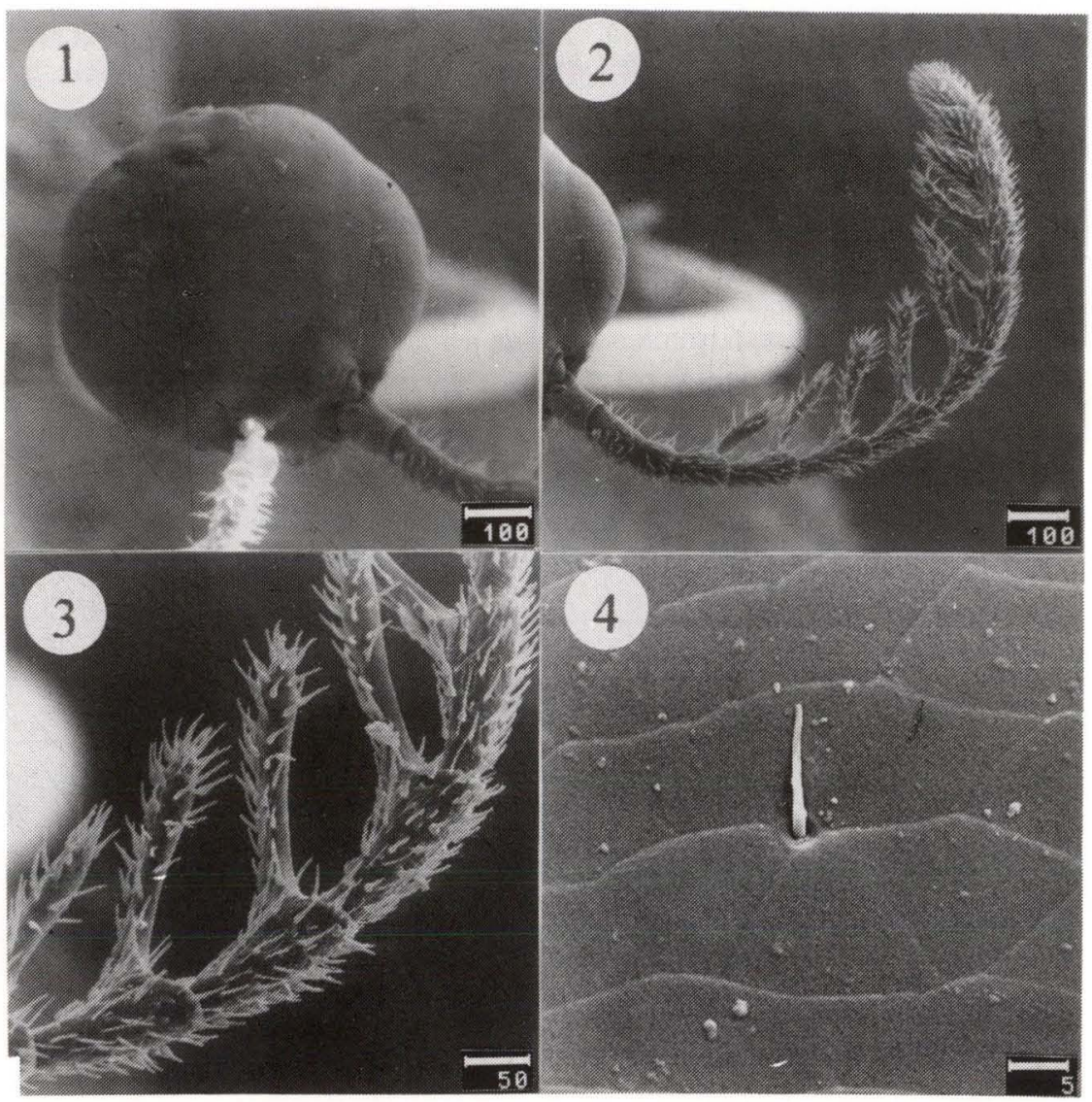

Figs 1-4. Calyozina dilatata sp.n. (1) Cabeça, dorsal; (2) antena, dorsal; (3) detalhe da antena, dorsal; (4) textura da cabeça, dorsal. (escala em $\mu \mathrm{m}$ ).

interligadas por qualquer sulco e distantes uma da outra 0,5 vezes seus diâmetros e distantes da margem lateral do escutelo por menos da metade dos seus diâmetros. Escutelo 1,25 vezes mais longo do que o mesoscuto e 0,91 vezes mais longo do que o pronoto. Disco propodeal tão longo quanto largo, com três carenas discais fortes e completas, pouco convergentes posteriormente, com carenas sublaterais e laterais que se unem no canto posterior do disco, que é foveolado; espaço entre todas as carenas com estrias transversais evidentes e posteriormente com esculturação irregular mais fraca; disco propodeal ligeiramente convexo no perfil, carena transversal posterior evidente, espiráculo do propódeo em uma cova arredondada no disco ântero-lateralmente; declividade do propódeo com uma carena mediana e com estrias tranversais, sinuosas e muito suaves. Propleura mais imbricada anteriormente, porém desprovida de pêlos e com microestrias longitudinais. Mesopleura fracamente imbricada, com uma fóvea rasa, aberta posteriormente, quase tão grande 
quanto a própria a mesopleura e com uma cova pequena no centro. Metapleura com estrias longitudinais fortes, porção inferior com duas depressões pequenas, que aparentemente são ocupadas pelas pernas mediana e posterior quando em repouso. Pleurosterno totalmente separado da mesopleura por uma carena conspícua, retilínea posteriormente e arqueada para cima anteriormente. Mesosterno com sulco mediano muito largo na metade posterior, com duas covas subtriangulares, laterais ao sulco mediano e justapostas à margem posterior. Metasterno alongado, com margens laterais e posterior elevadas, abauladas medianamente. Pernas com a mesma textura do tórax, tarsômero distal da perna anterior distintamente dilatado (Fig. 6). Fêmur anterior duas vezes mais longo do que largo, tíbias não espinhosas.

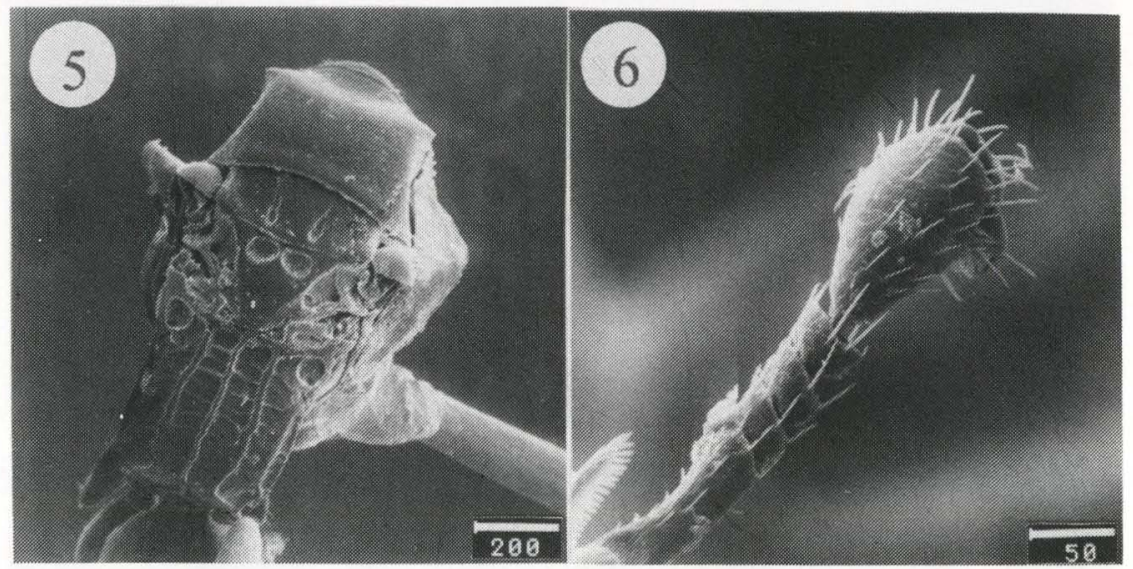

Figs 5-6. Calyozina dilatata sp.n. (5) Mesosomo, dorsal; (6) tarso anterior, lateral. (escala em $\mu \mathrm{m})$.

Gáster. Não peciolado, metade anterior dos segmentos com a mesma textura do tórax, com microestrias circulares e a metade posterior polida. Do terceiro tergito em diante com duas fileiras de pêlos longos e pálidos dirigidos para trás. Porção terminal do gáster comprimida lateralmente. Porção lateral do tergito III em diante tocando-se ventralmente e encobrindo toda a margem anterior dos esternitos. Mesosomo 1,19 vezes mais longo do que o gáster. Hipopígeo subtriangular, com ápice arredondado e voltado para trás, margem anterior com um dente mediano curto e delgado, quatro vezes menor do que o hipopígeo. Genitália estreita e alongada, com parâmero grande, maior do que a base da genitália, ápice amplamente truncado, com cantos arredondados e com alguns pêlos na face externa; volsela com cúspide ligeiramente menor do que o parâmero, cilíndrica e com ápice arredondado, dígito alongado, com a margem superior um pouco ondulada; edeago dividido em dois lobos longitudinais conspícuos com ápices pontiagudos; anel basal com seção transversal subcircular.

Material examinado. Holótipo e três parátipos machos: BRASIL, Amazonas: Manaus (Reserva Campina armadilha adesiva, 1 metro), 19-VI-1992, J. Vidal \& J. Vidal leg. (INPA). 
Etimologia. Do latim dilatata $=$ dilatado, em alusão ao tarsômero distal anterior distintamente dilatado.

Discussão. Esta espécie possue três características distintas em relação às demais espécies do gênero, a saber: gáster distintamente comprimido, quinto tarsômero anterior dilatado e asas fortemente tingidas de marrom.

As espécies de Calyozina diferenciam-se, principalmente, pelo grau de desenvolvimento dos processos pectinados das antenas, que variam nos segmentos medianos desde 0,3 até três vezes o comprimento do segmento; número de dentes apicais das mandíbulas, variando de 2 a 5; forma do canto anterior do disco pronotal, que pode ser arredondado ou cônico; número de carenas do disco propodeal, variando de 1 a 5; e pela textura do corpo, podendo ser quase polido, alutáceo, imbricado ou fortemente pontuado.

AGRADECIMENTOS. Ao Dr. J.A. Rafael pelo empréstimo do material do INPA e ao M.T. Tavares pela triagem de Bethylidae do mesmo.

\section{REFERÊNCIAS BIBLIOGRÁFICAS}

EnderleIN, G. 1912. H. Sauter's Formosa-Ausbeute. Braconidae, Proctotrupidae und Evaniidae (Hymenoptera). Entomol. Mit. 1 (9): 257-267.

Evans, H.E. 1964. A sinopsis of the American Bethylidae (Hymenoptera, Aculeata). Bull. Mus. Comp. Zool., Harvard, 132 (1): 1-222. 1965. Further studies on neotropical Epyrini (Hymenoptera, Bethylidae). Psyche, Cambridge, 72 (4): 265-278.

1978. New neotropical Calyozina, with key to species (Hymenoptera, Bethylidae). Entomol. News 89 (1/2): 61-62.

Harris, R.A. 1979. A glossary of surface sculpturing. Oc. Pap. Entomol. 28:1-31. KromBeIN, K.V. 1990. Systematics notes on some Bethylidae from Botswana: Epyrinae (Hymenoptera, Aculeata). Proc. Entomol. Soc. Wash. 92 (1): 98-105. . 1992. Systematics of the genera of Epyrini with ramose male antennae (Hymenoptera, Bethylidae). Proc. Entomol. Soc. Wash. 94 (3): 345-360.

Recebido em 07.VI.1996; aceito em 28.XII.1996 